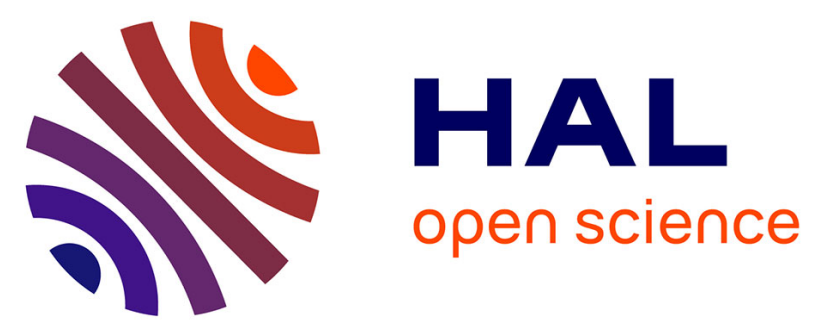

\title{
Mitochondrial Dysfunction and Lipid Accumulation in the Human Diaphragm during Mechanical Ventilation
}

Martin Picard, Boris Jung, Feng Liang, Ilan Azuelos, Sabah Hussain, Peter

Goldberg, Richard Godin, Gawiyou Danialou, Rakesh Chaturvedi, Karolina

Rygiel, et al.

\section{To cite this version:}

Martin Picard, Boris Jung, Feng Liang, Ilan Azuelos, Sabah Hussain, et al.. Mitochondrial Dysfunction and Lipid Accumulation in the Human Diaphragm during Mechanical Ventilation. American Journal of Respiratory and Critical Care Medicine, 2012, 186 (11), pp.1141. 10.1164/rccm.201206-0982OC . hal-02546565

\section{HAL Id: hal-02546565 \\ https://hal.umontpellier.fr/hal-02546565}

Submitted on 18 Apr 2020

HAL is a multi-disciplinary open access archive for the deposit and dissemination of scientific research documents, whether they are published or not. The documents may come from teaching and research institutions in France or abroad, or from public or private research centers.
L'archive ouverte pluridisciplinaire HAL, est destinée au dépôt et à la diffusion de documents scientifiques de niveau recherche, publiés ou non, émanant des établissements d'enseignement et de recherche français ou étrangers, des laboratoires publics ou privés. 


\title{
Mitochondrial Dysfunction and Lipid Accumulation in the Human Diaphragm during Mechanical Ventilation
}

\author{
Martin Picard ${ }^{1,2,3 * \neq}$, Boris Jung 1,4,5*, Feng Liang ${ }^{1 *}$, Ilan Azuelos1, Sabah Hussain ${ }^{1,6}$, Peter Goldberg ${ }^{1,6}$, \\ Richard Godin7, Gawiyou Danialou', Rakesh Chaturvedi6, Karolina Rygiel' ${ }^{8}$, Stefan Matecki ${ }^{5}$, \\ Samir Jaber ${ }^{4,5}$, Christine Des Rosiers9, George Karpati ${ }^{10}$, Lorenzo Ferri ${ }^{11}$, Yan Burelle ${ }^{7}$, \\ Douglass M. Turnbull8, Tanja Taivassalo ${ }^{2,3,10}$, and Basil J. Petrof ${ }^{1}$

\begin{abstract}
${ }^{1}$ Meakins-Christie Laboratories, ${ }^{2}$ Department of Kinesiology and Physical Education, ${ }^{3}$ Respiratory Epidemiology and Clinical Research Unit, and ${ }^{10}$ Montreal Neurological Institute, McGill University, Montreal, Quebec, Canada; ${ }^{4}$ Anesthesiology and Critical Care Department, Saint Eloi Hospital, and ${ }^{5}$ Institut National de la Santé et de la Recherche Médicale U-1046, Arnaud de Villeneuve Hospital, Centre Hospitalier Universitaire, Montpellier, France; ${ }^{6}$ Critical Care and Respiratory Divisions and ${ }^{11}$ Department of Thoracic Surgery, McGill University Health Centre and Research Institute, Montreal, Quebec, Canada; ${ }^{7}$ Faculty of Pharmacy and ${ }^{9}$ Montreal Heart Institute, Université de Montréal, Montreal, Quebec, Canada; and ${ }^{8}$ Mitochondrial Research Group, Centre for Brain Ageing and Vitality, Newcastle University, Newcastle, United Kingdom
\end{abstract}

Rationale: Mechanical ventilation (MV) is associated with adverse effects on the diaphragm, but the cellular basis for this phenomenon, referred to as ventilator-induced diaphragmatic dysfunction (VIDD), is poorly understood.

Objectives: To determine whether mitochondrial function and cellular energy status are disrupted in human diaphragms after MV, and the role of mitochondria-derived oxidative stress in the development of VIDD.

Methods: Diaphragm and biceps specimens obtained from brain-dead organ donors who underwent MV (15-176 h) and age-matched control subjects were compared regarding mitochondrial enzymatic function, mitochondrial DNA integrity, lipid content, and metabolic gene and protein expression. In addition, diaphragmatic force and oxidative stress after exposure to MV for $\mathbf{6}$ hours were evaluated in mice under different conditions.

Measurements and Main Results: In human MV diaphragms, mitochondrial biogenesis and content were down-regulated, with a more specific defect of respiratory chain cytochrome-c oxidase. Laser capture microdissection of cytochrome-c oxidase-deficient fibers revealed mitochondrial DNA deletions, consistent with damage from oxidative stress. Diaphragmatic lipid accumulation and responses of master cellular metabolic sensors (AMP-activated protein kinase

\footnotetext{
* These authors contributed equally to this work.
}

${ }^{\ddagger}$ Current address: Center for Mitochondrial and Epigenomic Medicine, Children's Hospital of Philadelphia and University of Pennsylvania, Philadelphia, PA.

Supported by grants from the McGill University Health Centre Research Institute (B.J.P., P.G.); Canadian Institutes of Health Research (B.J.P., T.T., S.H., C.D.R., Y.B., M.P.); Natural Sciences and Engineering Research Council of Canada (T.T., S.H., Y.B., M.P.); Fonds de Recherche en Santé du Québec (T.T., Y.B., McGill University Health Centre members); INSERM (S.M., S.J.); Societé Française d'Anesthésie Réanimation and Association Pour l'Assistance et la Réhabilitation à Domicile (B.J.); and the Newcastle University Centre for Brain Ageing and Vitality (D.M.T.).

Author Contributions: B.J.P. and T.T. supervised the study. All authors participated in the study design. P.G., G.D., R.C., S.M., S.J., G.K., and L.F. were involved in surgical procurement of muscle specimens from patients. M.P. designed and performed the histologic, biochemical, electron microscopy, and molecular genetics experiments with assistance from R.G. and K.R.; analyzed the data; prepared the figures; and wrote the manuscript with B.J.P. and T.T. B.J. and I.A. conducted the animal experiments. F.L. performed the gene expression experiments. Y.B. provided experimental reagents. B.J.P., M.P., B.J., I.A., F.L., T.T., S.H., C.D.R., D.M.T. , and R.G. were involved in data analysis and preparation of the manuscript.

Correspondence and requests for reprints should be addressed to Basil J. Petrof, M.D., Meakins-Christie Laboratories, 3626 Saint Urbain Street, Montreal, PQ, H2X 2P2 Canada. E-mail: basil.petrof@mcgill.ca

This article has an online supplement, which is accessible from this issue's table of

\section{AT A GLANCE COMMENTARY}

Scientific Knowledge on the Subject

Mechanical ventilation (MV) is associated with diaphragmatic dysfunction in humans and animal models, but little is known about the underlying cellular triggers and molecular mechanisms.

\section{What This Study Adds to the Field}

This study shows that mitochondrial function is severely disrupted in human MV diaphragms, with impaired mitochondrial biogenesis and enzymatic activities, and mitochondrial DNA damage. Furthermore, a transgenic mouse model points to mitochondria-derived oxidative stress as a likely trigger of ventilator-induced diaphragmatic dysfunction. Finally, metabolic substrate oversupply in MV diaphragms is identified as a potential instigator of mitochondrial dysfunction and oxidative stress under these conditions, thus suggesting new therapeutic avenues in patients with diaphragmatic dysfunction and weaning failure.

and sirtuins) were consistent with energy substrate excess as a possible stimulus for these changes. In mice, induction of hyperlipidemia worsened diaphragmatic oxidative stress during MV, whereas transgenic overexpression of a mitochondria-localized antioxidant (peroxiredoxin-3) was protective against VIDD.

Conclusions: Our data suggest that mitochondrial dysfunction lies at the nexus between oxidative stress and the impaired diaphragmatic contractility that develops during MV. Energy substrate oversupply relative to demand, resulting from diaphragmatic inactivity during MV, could play an important role in this process.

Keywords: ventilator-induced diaphragmatic dysfunction; oxidative stress; mitochondrial DNA; metabolic oversupply; diaphragmatic fatigue

Mechanical ventilation (MV) is one of the most frequently used interventions in the intensive care unit. Respiratory muscle dysfunction is often an important factor in the inability to successfully wean patients from MV (1-3), leading to an increase in medical complications and healthcare costs (4). Respiratory muscle weakness in this setting is likely related in part to the fact that MV itself causes diaphragmatic muscle fiber atrophy and injury in animals and humans (5-7), a condition termed ventilator-induced diaphragmatic dysfunction (VIDD) (8). The diaphragm, in contrast to other skeletal muscles, is normally activated rhythmically on a 24-hour basis. MV imposes a unique 
form of muscle disuse on the diaphragm, because the latter is simultaneously mechanically unloaded, intermittently shortened, and electrically suppressed by the ventilator breaths (9). Under these conditions, the energetic requirements of the diaphragm muscle fibers are also greatly reduced.

A large body of evidence points to oxidative stress as an essential element in the development of VIDD (10-14), but the primary source of increased reactive oxygen species (ROS) generation in the diaphragms of patients undergoing MV remains unclear (9). In addition, the underlying driving mechanisms that initiate and sustain excessive ROS production from diaphragmatic muscle fibers during MV are poorly understood. It is known that when energy substrate supplies substantially exceed cellular demands, this can trigger increased ROS production from mitochondria (15-17), a mechanism that has been implicated in the pathogenesis of metabolic syndrome and type 2 diabetes (18-21). In this regard, excessive mitochondrial superoxide production is a common feature of several metabolic oversupply models (20), and can damage mitochondrial DNA (mtDNA) $(22,23)$ and induce insulin resistance as a protective mechanism to mitigate this process (24). Cellular sensing of energetic oversupply also leads to a down-regulation of mitochondrial biogenesis (25), which further compromises mitochondrial function. Whether or not such a situation exists in the diaphragm during MV has not been studied. However, a decrease in mitochondrial function resulting from MV would be especially ill-suited to the situation faced by the diaphragm during attempts at weaning from the ventilator, when the energetic demands placed on the muscle are suddenly and substantially increased.

In the present study, we hypothesized that MV could trigger two major deleterious effects on diaphragmatic mitochondrial function. First, the reduced energy requirements of the diaphragm during MV might be "appropriately" interpreted as a signal to down-regulate mitochondrial biogenesis and enzymatic function. Second, a state of relative energetic oversupply versus demand induced by the lack of diaphragmatic activity during MV could exist, which favors increased mitochondrial ROS production (15-17). This could have damaging effects on the mitochondrial genome and other cellular components. All of these changes would be anticipated to increase the susceptibility of the diaphragm to muscle weakness and fatigue, thereby contributing to weaning failure.

To test our hypothesis, we studied the diaphragms of braindead organ donor patients who received MV in the intensive care unit before organ harvest, and compared these specimens with control diaphragmatic biopsies obtained during thoracic surgery for removal of solitary lung nodules. In addition, proof-ofconcept experiments to evaluate the roles of metabolic oversupply and mitochondria-derived oxidative stress in the pathogenesis of VIDD were performed in mechanically ventilated mice. Taken together, our findings suggest that mitochondrial abnormalities lie at the center of VIDD pathogenesis, leading us to propose a novel paradigm for VIDD in which metabolic oversupply could act as a key instigator of mitochondrial dysfunction and oxidative stress in the mechanically ventilated diaphragm. Some of the results of these studies have been previously reported in the form of abstracts (26-28).

\section{METHODS}

\section{Human Study Subjects}

Diaphragm and biceps muscle specimens were removed from brain-dead organ donors who had undergone MV (MV group, $\mathrm{n}=11$ ) for variable periods of time; the biopsies were surgically obtained in the operating room before circulatory arrest and organ harvest and immediately frozen in liquid nitrogen (for biochemical and molecular analyses) or cooled isopentane (for histology). Controls consisted of diaphragm samples obtained from age-matched patients during thoracic surgery for benign or malignant lung nodules $(\mathrm{n}=15)$, and biceps biopsies from individuals with muscle complaints who were subsequently declared to be normal $(n=7)$. The biceps from patients with MV was used as an internal control muscle to account for any medication or other nonspecific effects of critical illness on skeletal muscle properties.

\section{Histochemical, Biochemical, Microscopic, and Molecular Analyses}

The online supplement contains details regarding ethics approval, reagents, mitochondrial enzymatic activity assays in muscle homogenates, RNA extraction and real-time quantitative polymerase chain reaction (qPCR), gene expression profile analysis, total lipid quantification and lipid droplet confocal imaging, in situ histochemical detection of respiratory chain deficiency, single-cell mtDNA deletion analyses, Western blotting including protein carbonyl measurements, and electron microscopy methods. A complete listing of DNA primers and probes used in the study is also available in the online supplement (see Tables E3 and E4).

\section{Mouse MV Studies}

Wild-type and Prx-3 transgenic (29) mice (all C57BL/6 background) underwent MV for 6 hours under general anesthesia as detailed in the online supplement, and contractile force measurements of the diaphragm were performed as previously described (30). A subset of mice were injected with the hyperlipidemia-inducing drug P407 (31) 24 hours before MV.

\section{Statistical Analysis}

Means \pm SEM are presented for all data, and statistical methods are detailed in the online supplement. Because of limited amounts of biopsy material, certain analyses could not be performed in all human subjects, and the number of subjects for each variable is specifically indicated in each figure legend. The Mann-Whitney test was applied to compare groups in most cases unless stated otherwise, with statistical significance set at $P$ less than 0.05 .

\section{RESULTS}

\section{Characteristics of Human Study Subjects}

The clinical and demographic characteristics of the MV and control group subjects are shown in Tables E1 and E2. None of the control group subjects had experienced weight loss or other systemic manifestations of illness before surgery. The biceps was used as a nonrespiratory and nonweightbearing control muscle in both groups to ascertain whether changes in muscle properties associated with MV were specific to the diaphragm. There were no significant differences in the mean ages of the MV cohort (55 $\pm 5 \mathrm{yr})$ and the control diaphragm $(58 \pm 4 \mathrm{yr} ; P=0.86)$ or control biceps $(47 \pm 3 \mathrm{yr} ; P=0.13)$ subjects. The MV cohort was mechanically ventilated for an average period of $57 \pm 13$ hours (range, 15-176 h), whereas MV in control subjects was limited to the duration of surgery (range, 2-3 h).

\section{Mitochondrial Impairment and Reduced Mitochondrial Biogenesis in Human MV Diaphragms}

Impaired mitochondrial function was present in MV diaphragms, as indicated by reduced activity levels of the respiratory chain enzymes cytochrome- $c$ oxidase (COX) and succinate dehydrogenase (SDH) (Figures 1A and 1B). The mitochondrial matrix enzyme citrate synthase, a marker of mitochondrial content, also tended to be decreased in MV diaphragms (Figure 1C). 
The changes in COX and SDH were specific to the diaphragm, because activity levels of these enzymes did not differ significantly between MV and control subjects in the biceps muscle (Figures 1D-1F). Diaphragmatic COX and SDH values were normalized to citrate synthase to determine whether their reduced activity could be attributed to a lower mitochondrial content. After making this adjustment, COX activity remained significantly lower in MV diaphragms, whereas SDH activity did not differ from control subjects (Figures $1 \mathrm{G}$ and $1 \mathrm{H}$ ). This suggests that mitochondrial impairment in MV diaphragms involved intrinsic enzymatic dysfunction of COX.

Muscle oxidative capacity is controlled by transcriptional coactivators, such as peroxisome proliferator activated receptor- $\gamma$ coactivator (PGC)-1 $\alpha$ and PGC-1 $\beta$, which in turn act on downstream targets, such as mitochondrial transcriptional factor $\mathrm{A}$ (TFam). As one potential mechanism for mitochondrial abnormalities in MV diaphragms, several genes encoding proteins that promote mitochondrial biogenesis by acting on either nuclear DNA (Figure 2A) or mtDNA (Figure 2B) were found to be down-regulated. Other factors responsible for mitochondrial dynamics (fusion and fission), which are essential for proper functioning and mtDNA integrity, were also reduced (Figure 2C). As shown by the broader transcriptome (mRNA) analysis for each of the individual subjects in Figure 2D, a clear distinction in gene expression signatures was apparent between MV and control diaphragms. Although most mitochondrial and related metabolic genes were down-regulated in the MV group, notable exceptions consisted of mitochondrial superoxide dismutase (SOD2), the protein translation inhibitor EIF4EBP1, and adipokines (adiponectin and leptin), all of which showed a pattern of up-regulation in most subjects with MV.

\section{Lipid Accumulation and Metabolic Oversupply in Human MV Diaphragms}

To further dissect the nature of the above metabolic disturbances, muscle sections were incubated with oil red $\mathrm{O}$ to assess lipid content. This revealed that the diaphragm, and to a smaller extent the biceps, contained a higher lipid content in the patients with MV (Figures 3A and 3B; see Figure E1). Although myofiber atrophy may have contributed to an increase in the muscle fiber volume occupied by lipids (Figures 3C-3E), there was also an increased average size of individual lipid droplets (Figure $3 F)$. Furthermore, transcript levels for fatty acid synthase and adipokines were also higher in MV group diaphragms, whereas muscle carnitine palmitoyl transferase-1, a transporter of fatty acids into mitochondria, was down-regulated in the MV group (Figures $3 \mathrm{G}$ and $3 \mathrm{H}$ ).

Increased lipid accumulation within MV diaphragms could indicate an increased influx of metabolic substrates into muscle fibers relative to energetic consumption. Therefore, to evaluate cellular energy balance, we examined the two major intracellular metabolic sensor systems, AMP-activated protein kinase (AMPK) (Figures 3I-3L; see Figure E2) and sirtuin (SIRT)
A

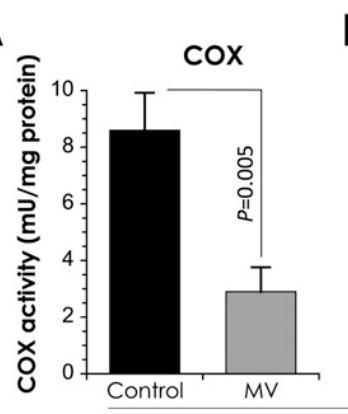

B

D

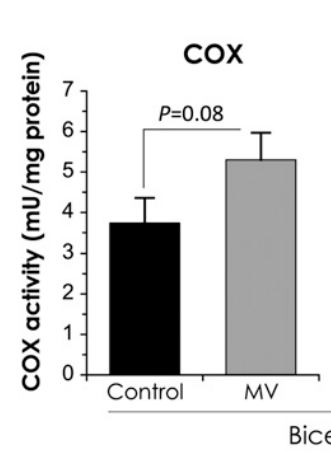

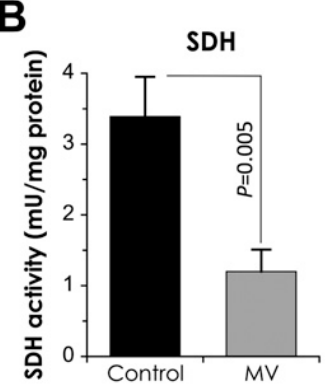

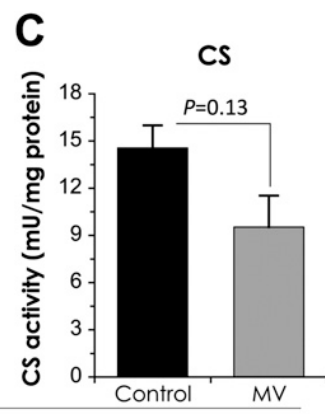

Diaphragm mitochondrial biomass and function
E

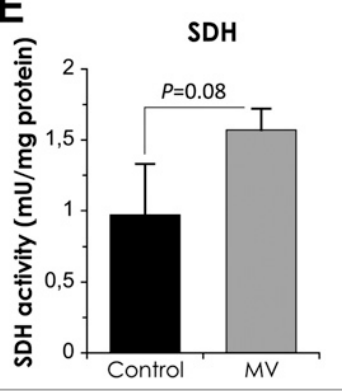

ceps mitochondrial biomass and function
F

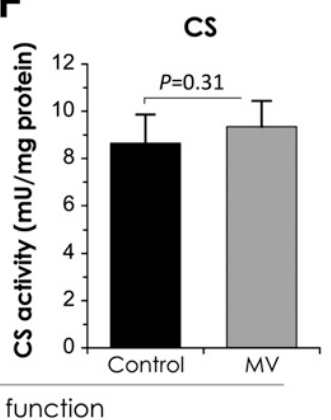

Figure 1. Reduced mitochondrial biomass and intrinsic respiratory chain dysfunction in human mechanically ventilated (MV) diaphragms. Enzymatic activity levels reflective of mitochondrial content and intrinsic respiratory chain functionality, determined in whole muscle homogenates, are shown for $(A$ and $D)$ mitochondrial cytochrome-c oxidase (COX), ( $B$ and $E$ ) succinate dehydrogenase (SDH), and ( $C$ and $F$ ) citrate synthase (CS). Mitochondrial respiratory chain complex-specific activities, as normalized to $\mathrm{CS}$ to adjust for mitochondrial content, are shown for $(G)$ COX (complex IV) and (H) SDH (complex II). A-C, G, and $H$ indicate data from MV and control group diaphragms; $\mathrm{n}=11$ per group. $D-F$ show data from $\mathrm{MV}$ and control group biceps; $n=7-10$ per group. Data are means \pm SEM.
G

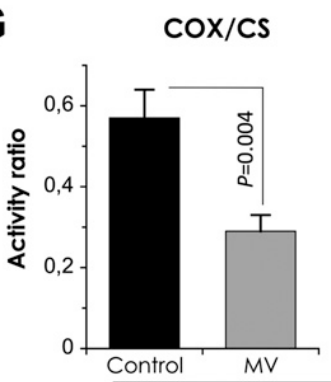

H

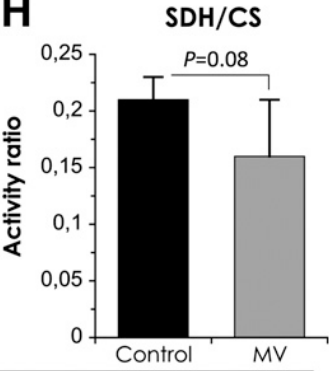

Diaphragm respiratory chain complex-specific function 


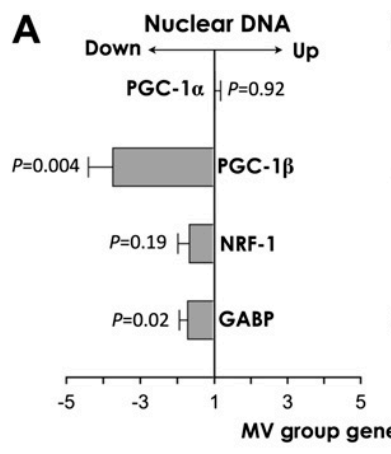

B
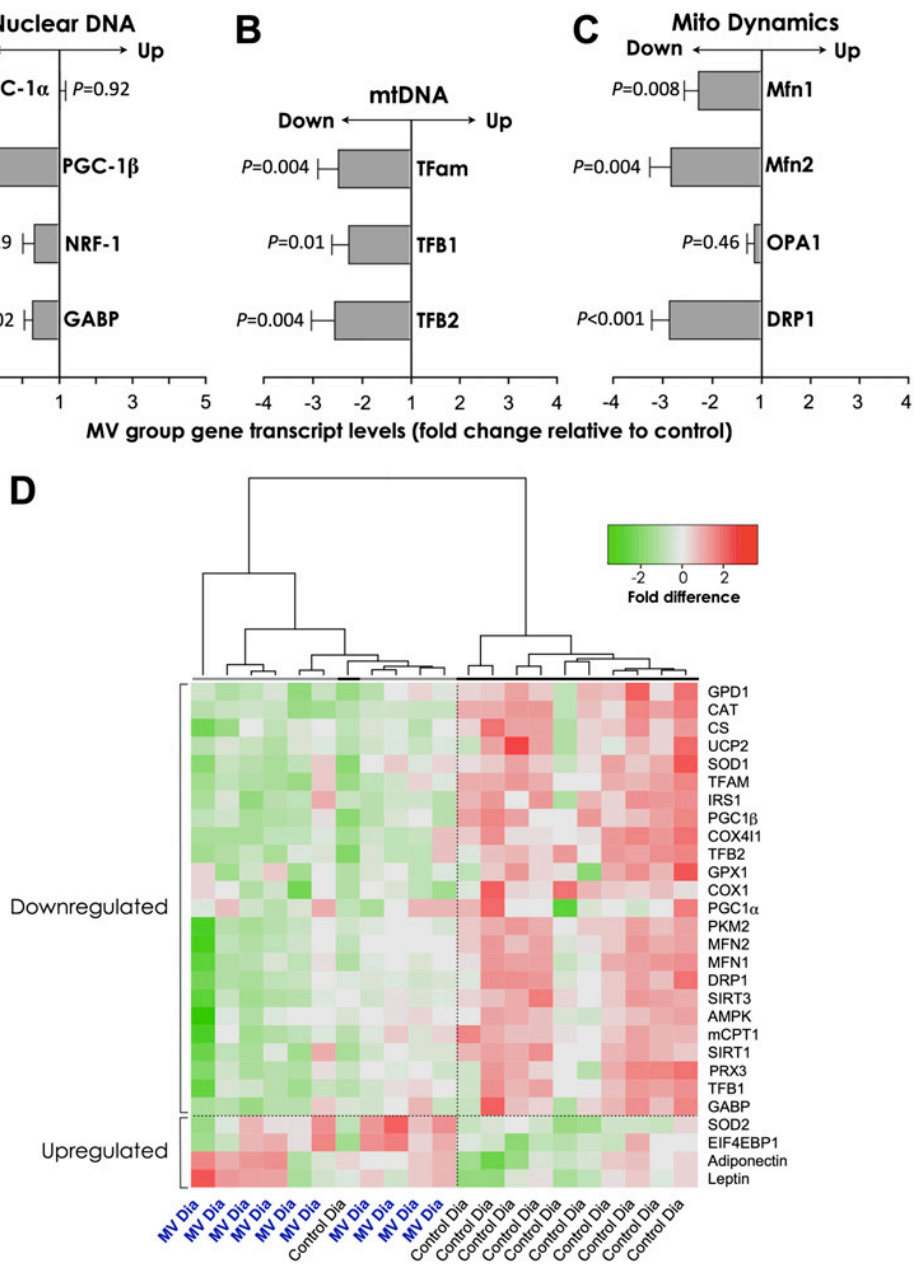

Figure 2. Impaired mitochondrial biogenesis in human mechanically ventilated (MV) diaphragms. Real-time quantitative polymerase chain reaction quantification of mRNA transcripts for key effectors of mitochondrial biogenesis acting on $(A)$ nuclear DNA, $(B)$ mitochondrial DNA, and (C) mitochondrial network dynamics; $\mathrm{n}=10$ for $\mathrm{MV}$ group, 7-11 for control subjects. (D) Heatmap of gene expression data with an unsupervised hierarchical clustering analysis of differentially expressed $(P<0.05)$ genes in diaphragms from control subjects and subjects with MV. The dendrogram atop the heatmap depicts the degree of similarity (shorter vertical lines indicating greater similarity) of gene expression profiles between individuals. Data are means \pm SEM. AMPK $=$ AMP-activated protein kinase; $\mathrm{CAT}=$ catalase; $\mathrm{CS}=$ citrate synthase; $\mathrm{COX} 1=$ cytochrome- $\mathrm{c}$ oxidase subunit 1 ; COX4I1 = cytochrome-c oxidase subunit 4 isoform $1 ; \mathrm{mCPT1}=$ carnitine palmitoyltransferase 1; DRP = dynamin-related protein; EIF4EBP1 = eukaryotic translation initiation factor $4 \mathrm{E}$ binding protein $1 ; \mathrm{GABP}=$ GA binding protein transcription factor subunit- $\alpha$; GPD = glycerol-3-phosphate dehydrogenase; GPX = glutathione peroxidase; IRS = insulin receptor substrate; $\mathrm{Mfn}=$ mitofusin; $\mathrm{NRF}=$ nuclear respiratory factor; $\mathrm{OPA}=$ optic atrophy; $\mathrm{PGC}=$ peroxisome proliferator activated receptor- $\gamma$ coactivator; PKM2 = pyruvate kinase muscle isozyme; Prx-3 = peroxiredoxin 3; SIRT = sirtuin; SOD = superoxide dismutase; TFam, TFB1, TFB2 = mitochondrial transcription factors $A, B 1$, and $B 2 ; \mathrm{UCP}=$ uncoupling protein.
1 and 3 (Figures $3 \mathrm{M}$ and $3 \mathrm{~N}$ ), which are down-regulated under conditions of energetic oversupply. In MV diaphragms, absolute levels of active (phosphorylated) AMPK protein were significantly lower than in control diaphragms. The mRNA levels for SIRT1 and SIRT3 (a mitochondrial sirtuin), which are implicated in antioxidant functions, mitochondrial biogenesis, and fatty acid oxidation, were similarly lower in the MV diaphragms. These findings, together with increased intracellular lipid, suggest the possible development of a state of energetic substrate oversupply in diaphragm muscle fibers when their workload is taken over by the ventilator.

\section{Mitochondrial DNA Damage in Human MV Diaphragm Muscle Fibers}

Oxidative stress is known to play a central role in the pathogenesis of VIDD, and mitochondria-derived ROS in particular have the potential to directly damage mitochondrial components, including mtDNA. In patients with myopathies resulting specifically from mtDNA deletions, double-staining of muscle fibers to assess SDH and COX activities in situ reveals a characteristic pattern, in which SDH (entirely encoded by nuclear DNA) staining is preserved, whereas COX (partially encoded by mtDNA) is absent. Such SDH-positive and COX-negative fibers were present at abnormally high levels in diaphragms from patients with MV (Figures 4A-4C; see Figure E3). To ascertain whether mtDNA deletions were indeed present within these fibers, two different approaches were used (Figure 4D). First, mtDNA from muscle homogenates was subjected to longrange PCR, demonstrating different PCR products consistent with multiple mtDNA deletions (Figure 4E). Second, COXnegative and COX-positive fibers were individually isolated from MV diaphragms using laser capture microdissection (Figure $4 \mathrm{~F}$ ), and assayed using multiplex qPCR directed against a region spanning the mitochondrial nicotinamide adenine dinucleotide reduced dehydrogenase (ND)-1 and ND-4 genes. This assay confirmed a significantly greater prevalence of mtDNA deletions in COX-negative fibers (Figure 4G; see Figure E4). Finally, given that mtDNA is particularly vulnerable to damage from mitochondria-derived ROS, we also quantified the transcript levels of antioxidant enzymes, which were generally down-regulated (Figure $4 \mathrm{H}$ ). However, of the two major mitochondrial antioxidants, SOD2 was up-regulated, whereas peroxiredoxin-3 (Prx-3), a mitochondria-specific scavenger of peroxides, demonstrated significant down-regulation in MV diaphragms.

\section{Metabolic Oversupply and Mitochondrial Oxidative Stress during MV in Mice}

To further probe the functional significance of metabolic substrate oversupply or mitochondria-derived oxidative stress during $\mathrm{MV}$, we next examined responses in mouse models. In wild-type mice the development of VIDD was rapid, with significantly reduced force-generating capacity of the diaphragm after 6 hours of MV (Figure 5A). Oxidative stress was evaluated by measuring carbonylated proteins, which were increased approximately sevenfold over control levels in the MV diaphragms (Figure 5B). As in humans, these changes were associated with increased lipid accumulation within MV diaphragms 
A

\begin{tabular}{l} 
ह \\
$\frac{0}{2}$ \\
$\frac{2}{0}$ \\
\hline 0
\end{tabular}

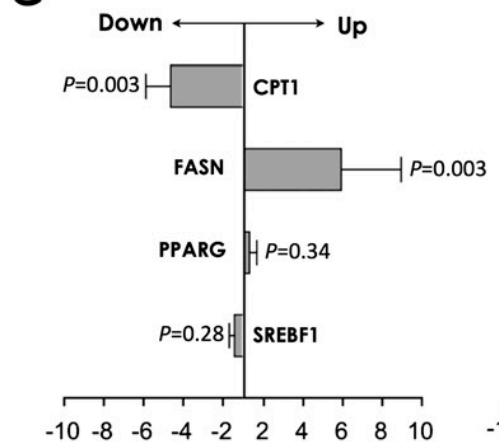

Control

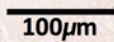

$100 \mu \mathrm{m}$
MV

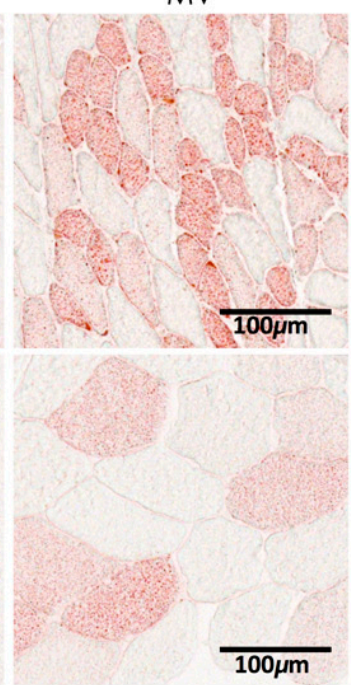

B

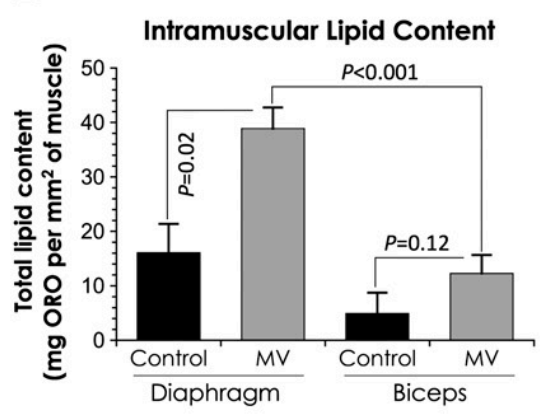

C

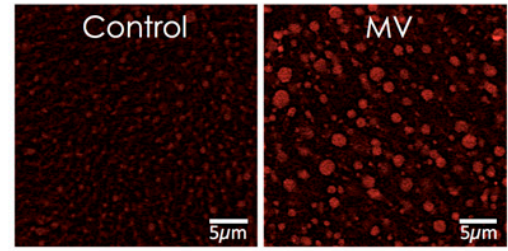

D
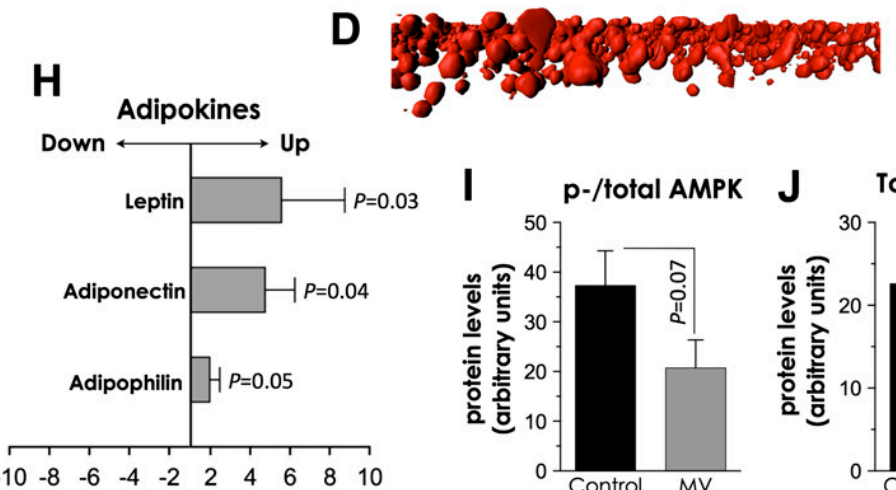

E

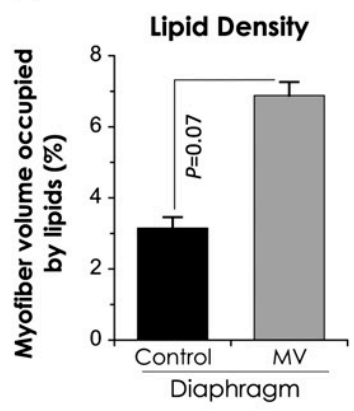

F

Froplet Volume

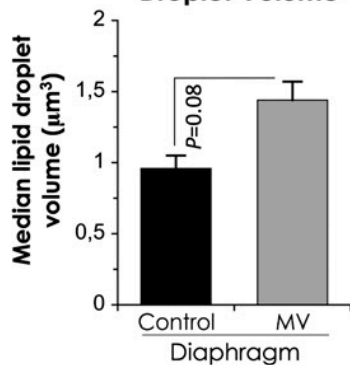

MV group gene transcript levels (fold change relative to control)

M

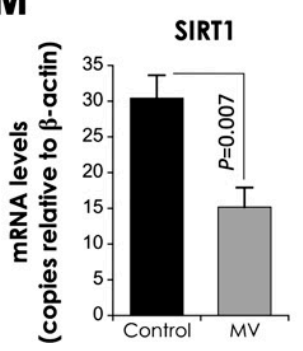

N

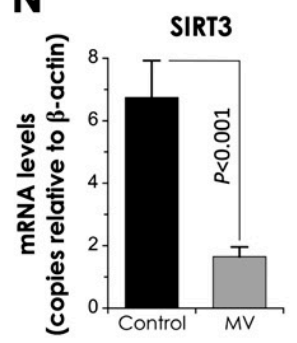

I
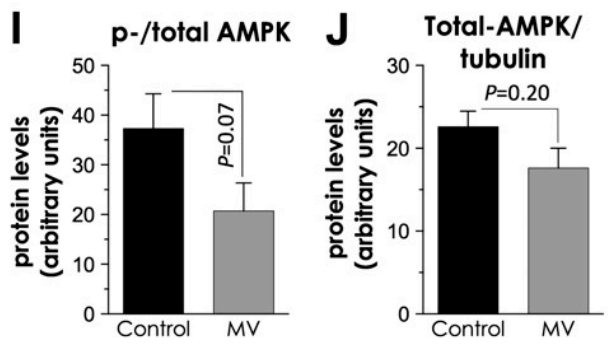

$\mathrm{K}$

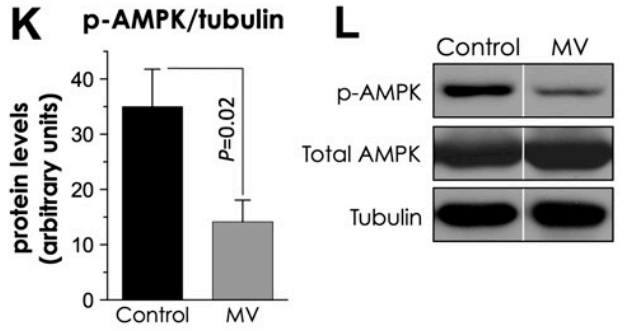

Figure 3. Increased lipid accumulation and metabolic oversupply in human mechanically ventilated (MV) diaphragms. (A) Oil red O lipid staining of diaphragm and biceps muscle sections from control subjects and individuals with MV. (B) Quantification of global intramuscular lipid content; $\mathrm{n}=$ 9-10 subjects for MV group, $\mathrm{n}=4-6$ for control subjects. (C) Confocal imaging of oil red O-stained muscle. (D) Three-dimensional reconstruction to quantify intramyocellular lipid droplet $(E)$ density and $(F)$ volume; $\mathrm{n}=3$ per group. $(G)$ Real-time polymerase chain reaction quantification of mRNA levels of key genes associated with lipid transport and synthesis, and $(H)$ lipid content (adipokines); $\mathrm{n}=10$ for MV group, $\mathrm{n}=11$ for control subjects. (I) Phosphorylation (activation) status of the cellular energy sensor and inducer of mitochondrial biogenesis, AMP-activated protein kinase (AMPK), relative to total AMPK levels; (I) total AMPK levels relative to the housekeeping gene tubulin; $(K)$ phosphorylated AMPK levels relative to tubulin; and $(L)$ representative immunoblot image $(n=7$ per group; all samples were run on the same gel for a given protein as shown in Figure E2). $(M)$ Real-time polymerase chain reaction quantification of mRNA levels for sirtuin (SIRT) 1, and $(N)$ SIRT3; $n=10-11$ per group. Data are presented as means \pm SEM. CPT1 = muscle carnitine palmitoyltransferase $1 ;$ FASN $=$ fatty acid synthase; PPARG = peroxisome proliferator activated receptor- $\gamma$; SREBF1 = sterol regulatory element binding factor 1.

(Figures 5C and 5D). Next, the drug P407 was used to induce an acute and reproducible hyperlipidemic state, to increase lipid substrate availability to the diaphragm during MV (see Figure E5). This tended to further suppress diaphragmatic force $(P=0.054)$ during MV (Figure 5E), and was also associated with a greater level of oxidative stress in the diaphragm (Figure 5F). Finally, to more specifically evaluate the role of mitochondria-derived oxidative stress in VIDD, we used transgenic mice overexpressing Prx-3, an antioxidant that is only present within mitochondria, and which is downregulated in human MV diaphragms. Importantly, Prx-3 mice maintained normal diaphragmatic force production (Figure $5 \mathrm{G})$, whereas carbonylated proteins in the diaphragm increased less than threefold (Figure $5 \mathrm{H}$ ) after MV, thus supporting a 
A

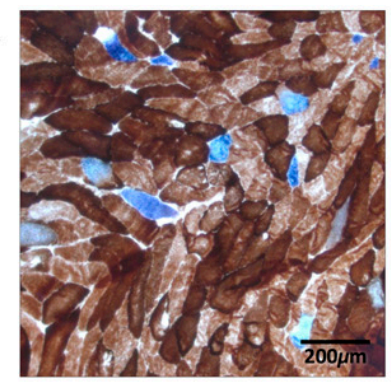

D

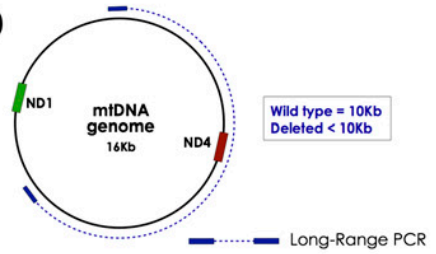

E

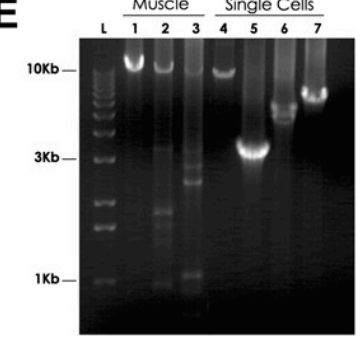

B

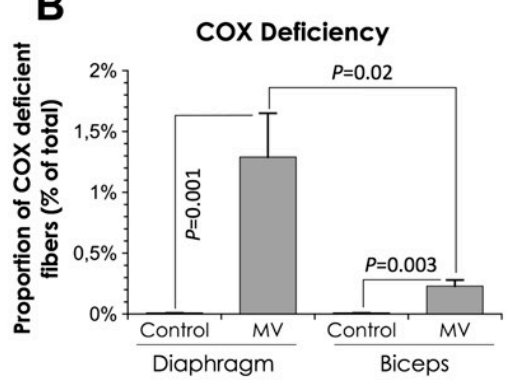

C
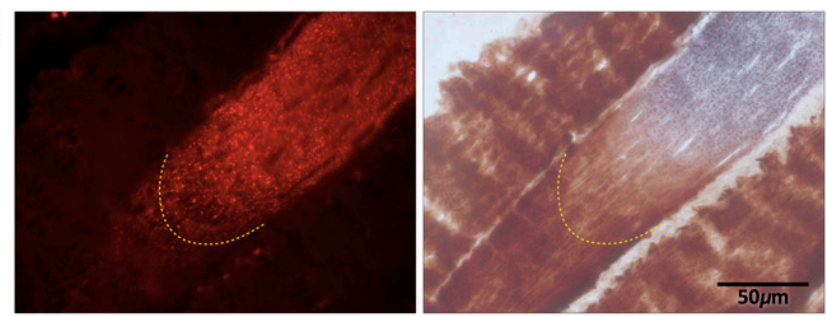

F

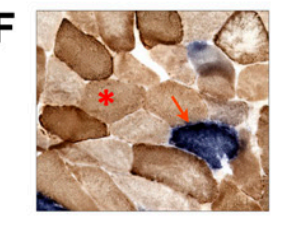

$\mathbf{F}^{\prime}$

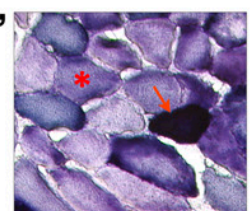

$F^{\prime}$

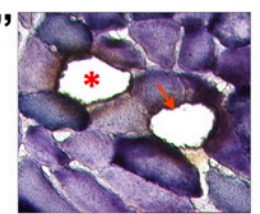

G

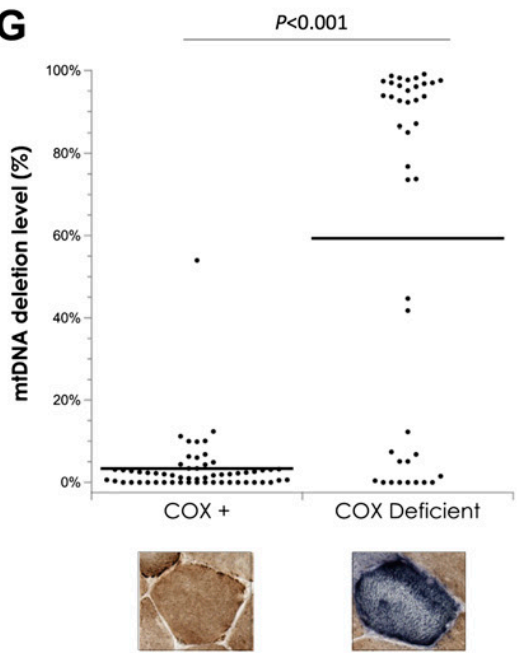

H

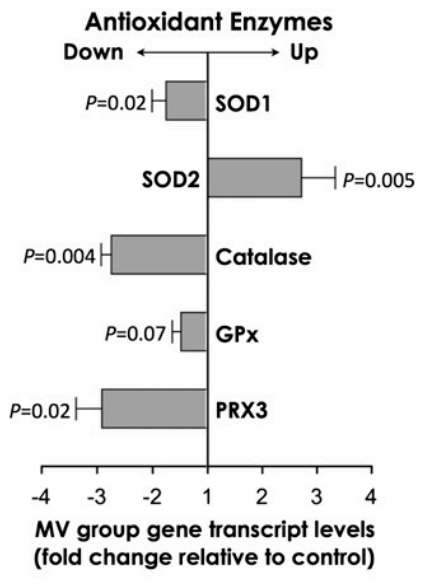

Figure 4. Muscle fibers with cytochrome-c oxidase (COX) selective respiratory chain deficiency and mitochondrial DNA deletions in human mechanically ventilated (MV) diaphragms. $(A)$ Muscle sections were sequentially stained for COX and succinate dehydrogenase (SDH) activity: blue-staining cells indicate respiratory chain deficiency selectively affecting COX. (B) The proportion of COX-deficient cells in COX-SDH-stained muscle sections was quantified by manually counting over 88,000 cells; $n=8-9$ for MV diaphragms and biceps, $n=7-8$ for control subjects. (C) Triple stained oil red O, COX, SDH muscle section visualized with epifluorescence (left, lipid droplets) and bright field (right, COX-SDH). (D) The major arc of the mtDNA genome was screened for deletions by long-range polymerase chain reaction (LR-PCR) in whole-muscle homogenates and single cells. Full length (no deletion) product is $10 \mathrm{~kb}$. (E) LR-PCR products resolved by agarose gel electrophoresis. Lanes 1-3: LR-PCR products of whole-muscle homogenates from subjects with MV (lower-molecular-weight products suggest mtDNA deletions in Lanes 2-3). Lanes 4-7: LR-PCR products from a single COX-positive cell (Lane 4) and three COX-deficient cells (Lanes 5-7) with lower-molecular-weight PCR products consistent with $\mathrm{mtDNA}$ deletions $(\mathrm{L}=$ ladder). Note that the presence of a DNA fragment less than $10 \mathrm{~kb}$ in Lane 7 , despite the absence of detectable deletion by the real-time nicotinamide adenine dinucleotide reduced [NADH] dehydrogenase (ND)1/ND4 qPCR assay, indicates that not all deletions involved the ND4 gene region. $(F)$ COX-positive (brown, example denoted by asterisk) and COX-deficient (blue, example denoted by arrow) cells were identified by double COX-SDH staining, and $\left(F^{\prime}\right)$ sections stained with SDH only were used for $\left(F^{\prime \prime}\right)$ laser capture microdissection of single cells of each type. $(G)$ Collected single muscle cells of either COX-positive $(n=57)$ or COX-deficient $(n=41)$ phenotype were individually screened for the common mtDNA ND4 deletion using the multiplex real-time qPCR ND1/ND4 assay. Horizontal bars represent means of each group (3.4 $\pm 1 \%$ for COX-positive, $59.3 \pm 6.7 \%$ for COX-deficient). (H) Real-time qPCR quantification of mRNA transcript levels for the antioxidant enzymes copperzinc superoxide dismutase (SOD1), manganese SOD (SOD2), catalase, glutathione peroxidase (GPx), and mitochondrial peroxiredoxin (PRX3); $n=$ $10-11$ per group. Data are means \pm SEM.

major role for mitochondria-derived ROS in the pathogenesis of VIDD.

\section{DISCUSSION}

Diaphragmatic strength and endurance are critical determinants of the ability to successfully remove patients from $\operatorname{MV}(1,3)$. Here we provide evidence that MV is associated with multiple changes in metabolic function of the diaphragm consisting of (1) mitochondrial respiratory chain deficiency, with a loss of COX enzymatic activity that is disproportionately large relative to reductions in mitochondrial content; (2) a generalized downregulation in the expression of mitochondrial biogenesis and antioxidant factors; (3) mitochondrial genome damage, as indicated by the presence of mtDNA deletions; and (4) signs of metabolic oversupply including increased lipid accumulation within diaphragmatic muscle fibers. Furthermore, through the use of a transgenic mouse model, we demonstrate that overexpression of an antioxidant specifically localized within mitochondria (Prx-3) completely abrogates the loss of diaphragmatic force-generating capacity, which defines the VIDD phenomenon. Thus, in the human and murine models, our data suggest that adverse alterations in mitochondrial function represent a critical pathophysiologic link between MV and ensuing diaphragmatic impairment.

Adequate mitochondrial function is a prerequisite for normal muscle oxidative capacity, and mitochondrial respiratory chain deficiency caused by mtDNA mutations is a known cause of exercise intolerance in humans $(32,33)$. The mitochondrial genome seems to be particularly vulnerable to ROS-induced DNA damage (34). Complex II (SDH) is entirely encoded by the nuclear genome, whereas several complex IV (COX) subunits are encoded by mtDNA. SDH activity did not differ between MV and control diaphragms after normalization to account for the reduced 
A

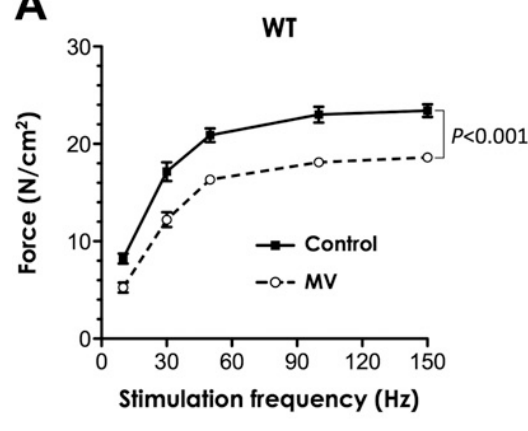

B

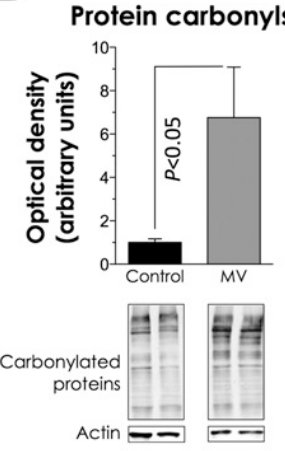

C

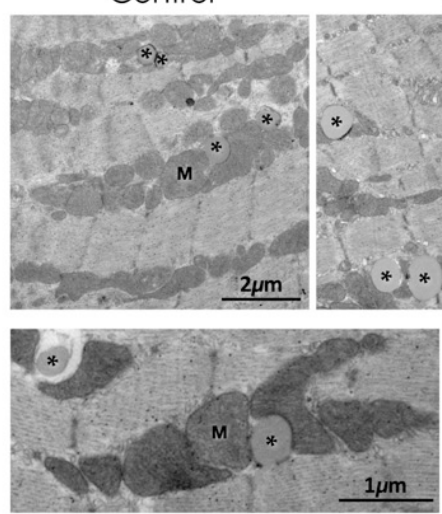

G

F Protein carbonyls

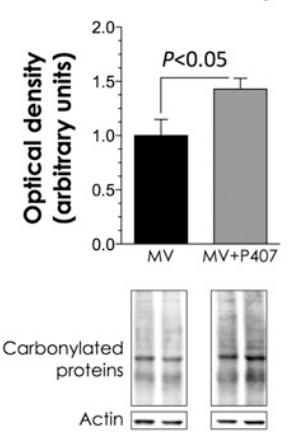

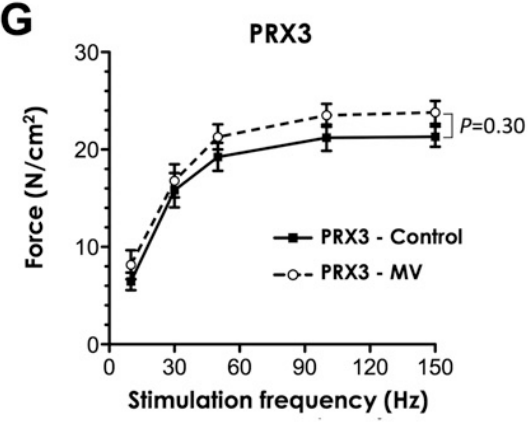

MV

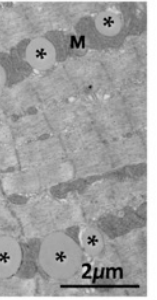

D

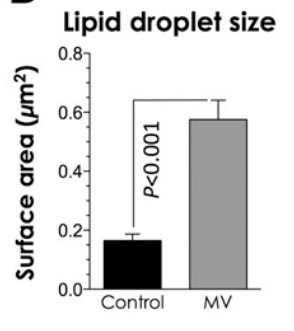

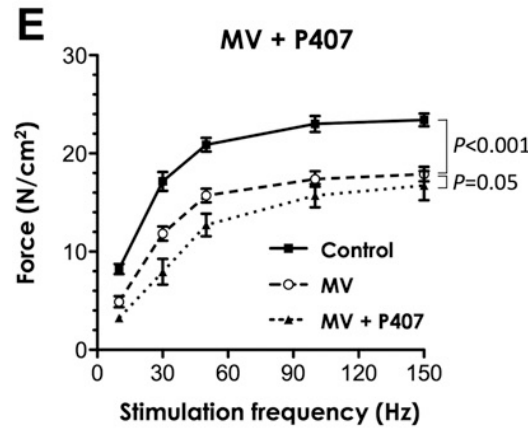

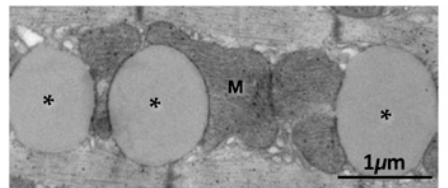

H Protein carbonyls

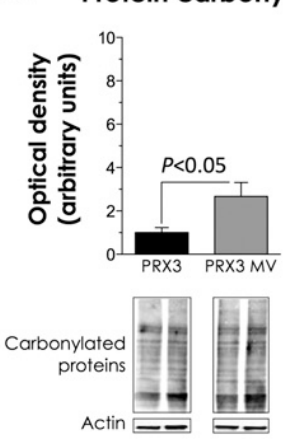

Figure 5. Effects of hyperlipidemia and transgenic overexpression of a mitochondria-specific antioxidant on ventilator-induced diaphragmatic dysfunction in mice. After wild-type (WT) mice were mechanically ventilated (MV) for 6 hours, $(A)$ diaphragmatic contractile force was reduced and $(B)$ diaphragmatic protein carbonylation (oxidative stress) was increased approximately sevenfold. In addition, electron microscopy revealed an increased size of lipid droplets (asterisks) in MV diaphragms ( $C$ and $D$ ), which were often found in close proximity to mitochondria ( $M$ ). The changes in $(E)$ diaphragmatic contractility and $(F)$ oxidative stress were exacerbated by the induction of hyperlipidemia with P407 treatment in WT mice. In transgenic mice overexpressing peroxiredoxin 3 (PRX3) exposed to MV for 6 hours, $(G)$ diaphragmatic force production remained normal and $(H)$ oxidative stress increased less than threefold. Data are means \pm SEM. $n=5$ per group for contractility; $n=4$ per group for protein carbonylation.

mitochondrial content found in the MV group. In contrast, a persistent deficiency of about $50 \%$ in COX activity was observed, and the COX-SDH costaining pattern in MV diaphragms (i.e., COX deficiency with maintenance of SDH staining) is further evidence for a specific impairment of mtDNA encoded subunits (35). This pattern is characteristic of patients with hereditary mutations of complex IV and other mitochondrial diseases associated with mtDNA deletions (35-37). It is also found at a much lower level in some elderly individuals $(37,38)$, in whom COX-deficient fibers are believed to reflect an increased proportion of mutant mtDNA copies resulting from cumulative oxidative stress-induced damage (39). An interesting aspect of mtDNA-mutated mitochondria is the ability to undergo local clonal expansion within individual fiber segments $(40,41)$. Such segmental COX deficiency was found in several diaphragm muscle fibers of the MV group, and the prevalence of COX-deficient fibers was also higher in older patients with MV (see Figures E6 and E7). However, it should be noted that although the increased presence of mtDNA deletions in human MV diaphragms may be caused by greater mitochondria-derived ROS, this remains to be determined.

Previous work in animal models and humans has shown that oxidative modifications are prominent in MV diaphragms (14, 42, 43). Our findings are consistent with these data, because mitochondria with deficient respiratory chain function can permit excessive electron leakage with consequent increases in ROS production (44). Oxidative stress has the potential to inhibit contractile mechanisms directly, and is also pivotal in triggering several proteolytic pathways implicated in muscle atrophy $(9,43)$. Mitochondrial biogenesis is generally accompanied by an up-regulation of antioxidant mechanisms (45). Therefore, the down-regulation of transcriptional regulators of mitochondrial biogenesis genes may explain the apparent inability of MV diaphragms to up-regulate antioxidant defenses. Only the mitochondria-specific isoform of SOD2 demonstrated a compensatory up-regulation in MV group diaphragms, which is in keeping with a mitochondrial source of oxidative stress (10, 11). However, increased SOD2 expression in MV diaphragms did not prevent respiratory chain deficiency and mtDNA damage. This may be because the end-product of SOD2 activity, $\mathrm{H}_{2} \mathrm{O}_{2}$, could not be effectively removed due to the substantial downregulation of catalase and Prx-3 expression levels in MV diaphragms. Indeed, although SOD2 relieves mitochondrial oxidative stress caused by superoxide, it also generates increased levels of $\mathrm{H}_{2} \mathrm{O}_{2}$ that can damage macromolecules including mtDNA (46). Such an explanation is supported by the fact that transgenic overexpression of Prx-3 (29), a mitochondria-specific scavenger of $\mathrm{H}_{2} \mathrm{O}_{2}$, allowed for preservation of diaphragmatic force production after MV in mice.

Although our findings and those of others $(10,11,42)$ establish the existence of mitochondrial functional abnormalities in MV diaphragms, an important question remains: what is the primary cellular stimulus for these events? There has been much recent interest in the relationship between metabolic 


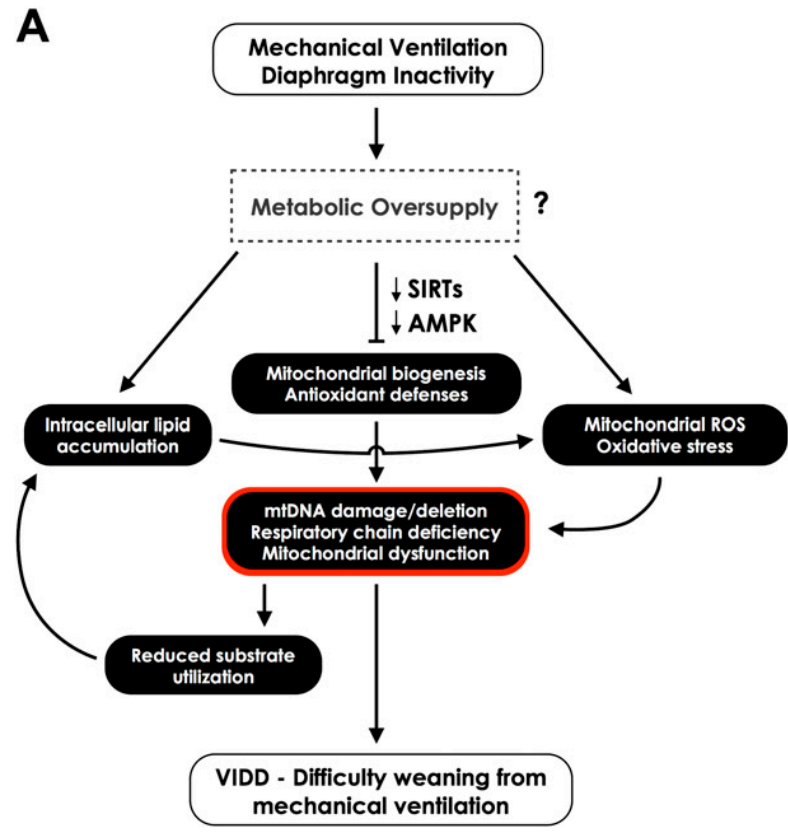

B

Figure 6. Proposed mechanistic scheme for diaphragmatic dysfunction during mechanical ventilation (MV). (A) Reduced contractile activity of the diaphragm during MV alters the energetic balance in the muscle, resulting in decreased mitochondrial biogenesis and enzymatic activity, with increased lipid accumulation and oxidative stress, the latter leading to mitochondrial DNA (mtDNA) damage. These changes compromise contractile function of the diaphragm during attempts at weaning from MV. (B) Under normal conditions in which there is appropriate metabolic balance in the diaphragm, electrons derived from energetic substrates are freely shuttled down the electron transport chain, as shown by the main arrow representing the driving force for electron flow. However, when energetic substrate supply greatly exceeds metabolic demand, electron flow is inhibited. This can be associated with reduced ATP synthesis and increased leakage of surplus electrons from the electron transport chain (mitochondrial overload). These surplus electrons can then react with surrounding molecular oxygen, leading to increased reactive oxygen species (ROS) generation from mitochondria (Complexes I and III). AMPK = AMP-activated protein kinase; p-AMPK = phosphorylated (activated) AMPK; SIRTs = sirtuins1 and 3; FFAs = free fatty acids; VIDD = ventilator-induced diaphragmatic dysfunction.

oversupply and increased mitochondrial ROS production as a cause of insulin resistance in the metabolic syndrome and type 2 diabetes $(15,18,21)$. An excess of intracellular energetic substrates relative to ATP demand leads to a build-up of electron donors (i.e., $\mathrm{NADH}, \mathrm{FADH}_{2}$ ) generated from the tricarboxylic acid (Krebs) cycle and $\beta$-oxidation pathway (15). Under such conditions of "mitochondrial overload" (18), electron flow down the respiratory chain is impeded, and this is associated with an increased probability of electrons leaking and interacting with molecular oxygen to form superoxide $(15,24)$. Furthermore, to the extent that metabolic oversupply is associated with increased intramyocellular lipids, the latter can react with ROS and themselves become potent sources of oxidative stress (lipotoxicity) (47), thus propagating the cycle of free radical generation and mitochondrial dysfunction (48). Our finding that intracellular lipid accumulation, COX deficiency, and mtDNA deletions can colocalize (see Figure 4C) is consistent with this notion. Indeed, exposure of muscle cells to saturated free fatty acids in vitro induces ROS-dependent mtDNA damage (23).

MV causes a sudden interruption of diaphragmatic contractile activity, such that the energetic requirements of the muscle are abruptly reduced. Because one of the main criteria for brain death is an absence of spontaneous respiratory activity, it can be assumed that patients with MV in our study lacked significant respiratory muscle activation for most of their intensive care unit stay. To determine whether a state of energetic oversupply might exist in the diaphragms of these patients, we examined the responses of two master sensors of cellular energy status, AMPK and SIRT1. AMPK is activated by increases in the intracellular AMP/ATP ratio, whereas SIRTs are nicotinamide adenine dinucleotide-dependent deacetylases (49). In the setting of energetic depletion, these two metabolic sensor systems are upregulated and synergize to promote mitochondrial biogenesis and fatty acid oxidation (50-53). Conversely, energetic oversupply is characterized by a functional down-regulation of AMPK and SIRTs $1 / 3$. Accordingly, the decreases in activated AMPK and SIRT expression, reduction of mitochondrial biogenesis transcription factor expression (which can also be explained by suppression of AMPK and SIRT signaling) (49), and presence of ectopic lipid within muscle fibers are all highly suggestive of a state of metabolic oversupply in human diaphragms subjected to major inactivity as a result of MV.

These findings lead us to propose a new hypothesis regarding the pathogenesis of VIDD, in which metabolic oversupply could represent a primary initiating factor, because it is capable of unifying the elements of mitochondrial respiratory chain deficiency, mitochondria-derived oxidative stress, and abnormal lipid accumulation found within diaphragms exposed to sustained MV (Figure 6). To the extent that patients in the intensive care unit often have high serum levels of metabolic substrates, such as glucose and free fatty acids (54), this might further exacerbate the situation by increasing substrate availability to the diaphragm during MV. This idea is supported by our observation that induction of hyperlipidemia further increased oxidative stress and tended to worsen diaphragmatic function in the mouse diaphragm exposed to MV. Indeed, it is interesting to note that the early delivery of high caloric intake with parenteral nutrition was recently associated with a prolongation of weaning time (55), whereas intensive insulin therapy to prevent hyperglycemia has been reported to accelerate the weaning process (56).

Finally, certain methodologic limitations of our study should be addressed. First, our sample size was relatively small, and the 
patients were heterogeneous in terms of past medical history. Second, many patients were transferred to our hospital from other institutions, and the ventilation mode before transfer was not always well documented. Third, patients in the control biceps cohort were different from the control diaphragm patients and tended to be younger, although the latter would be expected to exaggerate changes attributed to MV in the biceps and is thus unlikely to have affected our main conclusions. Finally, our study is not able to ascertain whether the preferential mitochondrial dysfunction and greater lipid accumulation observed after MV in the diaphragm (as compared with the nonrespiratory biceps muscle) results solely from MV-induced inactivity, or is also related to a greater intrinsic vulnerability of the diaphragm to systemic factors associated with critical illness. However, it should be noted that in either scenario, the ability to generate adequate intramuscular energy supplies upon a sudden resumption of diaphragmatic activity during weaning attempts would be impaired by the loss of mitochondrial function.

In summary, our findings suggest that MV is associated with the rapid development of metabolic dysregulation and mitochondrial respiratory chain deficiency in the human diaphragm, which may result at least in part from a state of energy substrate oversupply relative to demand in the muscle. Accordingly, clinical measures designed to restore metabolic balance in the diaphragm, such as reducing energetic substrate overload or increasing diaphragmatic contractile activity levels, should be useful in preventing these deleterious changes. Importantly, impaired mitochondrial function caused by metabolic oversupply can be rescued by activating the AMPK/PGC- $1 \alpha$ signaling axis $(57,58)$, which simultaneously up-regulates mitochondrial biogenesis and antioxidant defenses $(45,50)$. Therefore, pharmacologic agents with the capacity to stimulate AMPK (e.g., metformin) (59) and SIRT agonists (e.g., resveratrol) (60), or mitochondria-targeted antioxidant therapies $(10,61)$, particularly if initiated early in the course of MV, could all potentially be valuable adjuncts for mitigating the adverse consequences of MV on diaphragmatic function.

Acknowledgment: The authors are indebted to the patients and their families for their willingness to participate in this study, and to the cooperation of Transplant Quebec in this project. They thank Tong Li, Christian Lemaire, Johanne Bourdon, Mullah Abu Shadeque, and Zia Saleh for technical contributions; Robert Guérin, Dr. Erin O'Ferrall, and Dr. John Richardson for expert opinion on histologic work; Dr. Eric Shoubridge, Dr. Robert Taylor, and Dr. Nicholas Bertos for use of their facility; Dr. Hana Antonicka, Dr. Gilles Gouspillou, Dr. Julie Murphy, and the MRG members for technical assistance; Kathyrn White and Tracey Davey (EM Research Services, Newcastle University) for assistance with the electron microscopy work; and Dr. Hana Antonicka and Dr. Russ Hepple for useful comments on the manuscript.

\section{References}

1. Vassilakopoulos T, Zakynthinos S, Roussos C. The tension-time index and the frequency/tidal volume ratio are the major pathophysiologic determinants of weaning failure and success. Am J Respir Crit Care Med 1998;158:378-385.

2. Hermans G, Agten A, Testelmans D, Decramer M, Gayan-Ramirez G. Increased duration of mechanical ventilation is associated with decreased diaphragmatic force: a prospective observational study. Crit Care 2010;14:R127.

3. Tobin MJ, Laghi F, Brochard L. Role of the respiratory muscles in acute respiratory failure of COPD: lessons from weaning failure. $J \mathrm{Appl}$ Physiol 2009;107:962-970.

4. Esteban A, Ferguson ND, Meade MO, Frutos-Vivar F, Apezteguia C, Brochard L, Raymondos K, Nin N, Hurtado J, Tomicic V, et al. Evolution of mechanical ventilation in response to clinical research. Am J Respir Crit Care Med 2008;177:170-177.

5. Powers SK, Kavazis AN, Levine S. Prolonged mechanical ventilation alters diaphragmatic structure and function. Crit Care Med 2009;37:S347-S353.
6. Levine S, Nguyen T, Taylor N, Friscia ME, Budak MT, Rothenberg P, Zhu J, Sachdeva R, Sonnad S, Kaiser LR, et al. Rapid disuse atrophy of diaphragm fibers in mechanically ventilated humans. $N$ Engl J Med 2008;358:1327-1335.

7. Jaber S, Petrof BJ, Jung B, Chanques G, Berthet JP, Rabuel C, Bouyabrine H, Courouble P, Koechlin C, Sebbane M, et al. Rapidly progressive diaphragmatic weakness and injury during mechanical ventilation in humans. Am J Respir Crit Care Med 2010;183:364-371.

8. Vassilakopoulos T, Petrof BJ. Ventilator-induced diaphragmatic dysfunction. Am J Respir Crit Care Med 2004;169:336-341.

9. Petrof BJ, Jaber S, Matecki S. Ventilator-induced diaphragmatic dysfunction. Curr Opin Crit Care 2010;16:19-25.

10. Powers SK, Hudson MB, Nelson WB, Talbert EE, Min K, Szeto HH, Kavazis AN, Smuder AJ. Mitochondria-targeted antioxidants protect against mechanical-ventilation-induced diaphragm weakness. Crit Care Med 2011;39:1749-1759.

11. Tang H, Lee M, Budak MT, Pietras N, Hittinger S, Vu M, Khuong A, Hoang CD, Hussain SN, Levine S, et al. Intrinsic apoptosis in mechanically ventilated human diaphragm: linkage to a novel fos/foxo1/stat3-bim axis. FASEB J 2011;25:2921-2936.

12. Zergeroglu MA, McKenzie MJ, Shanely RA, Van Gammeren D, DeRuisseau KC, Powers SK. Mechanical ventilation-induced oxidative stress in the diaphragm. J Appl Physiol 2003;95:1116-1124.

13. Whidden MA, McClung JM, Falk DJ, Hudson MB, Smuder AJ, Nelson WB, Powers SK. Xanthine oxidase contributes to mechanical ventilationinduced diaphragmatic oxidative stress and contractile dysfunction. J Appl Physiol 2009;106:385-394.

14. Hussain SN, Mofarrahi M, Sigala I, Kim HC, Vassilakopoulos T, Maltais F, Bellenis I, Chaturvedi R, Gottfried SB, Metrakos P, et al. Mechanical ventilation-induced diaphragm disuse in humans triggers autophagy. Am J Respir Crit Care Med 2010;182:1377-1386.

15. Anderson EJ, Lustig ME, Boyle KE, Woodlief TL, Kane DA, Lin CT, Price JW III, Kang L, Rabinovitch PS, Szeto HH, et al. Mitochondrial $\mathrm{H}_{2} \mathrm{O}_{2}$ emission and cellular redox state link excess fat intake to insulin resistance in both rodents and humans. J Clin Invest 2009;119:573-581.

16. Yu T, Sheu SS, Robotham JL, Yoon Y. Mitochondrial fission mediates high glucose-induced cell death through elevated production of reactive oxygen species. Cardiovasc Res 2008;79:341-351.

17. Balaban RS, Nemoto S, Finkel T. Mitochondria, oxidants, and aging. Cell 2005;120:483-495.

18. Koves TR, Ussher JR, Noland RC, Slentz D, Mosedale M, Ilkayeva O, Bain J, Stevens R, Dyck JR, Newgard CB, et al. Mitochondrial overload and incomplete fatty acid oxidation contribute to skeletal muscle insulin resistance. Cell Metab 2008;7:45-56.

19. Petersen KF, Dufour S, Befroy D, Garcia R, Shulman GI. Impaired mitochondrial activity in the insulin-resistant offspring of patients with type 2 diabetes. $N$ Engl J Med 2004;350:664-671.

20. Muoio DM, Newgard CB. Mechanisms of disease: molecular and metabolic mechanisms of insulin resistance and beta-cell failure in type 2 diabetes. Nat Rev Mol Cell Biol 2008;9:193-205.

21. Houstis N, Rosen ED, Lander ES. Reactive oxygen species have a causal role in multiple forms of insulin resistance. Nature 2006;440:944-948.

22. Medikayala S, Piteo B, Zhao X, Edwards JG. Chronically elevated glucose compromises myocardial mitochondrial DNA integrity by alteration of mitochondrial topoisomerase function. Am J Physiol Cell Physiol 2011;300:C338-C348.

23. Rachek LI, Musiyenko SI, LeDoux SP, Wilson GL. Palmitate induced mitochondrial deoxyribonucleic acid damage and apoptosis in L6 rat skeletal muscle cells. Endocrinology 2007;148:293-299.

24. Hoehn KL, Salmon AB, Hohnen-Behrens C, Turner N, Hoy AJ, Maghzal GJ, Stocker R, Van Remmen H, Kraegen EW, Cooney GJ, et al. Insulin resistance is a cellular antioxidant defense mechanism. Proc Natl Acad Sci USA 2009;106:17787-17792.

25. Palmeira CM, Rolo AP, Berthiaume J, Bjork JA, Wallace KB. Hyperglycemia decreases mitochondrial function: the regulatory role of mitochondrial biogenesis. Toxicol Appl Pharmacol 2007;225:214-220.

26. Jung B, Mrozek S, Petrof BJ, Lacampagne A, Matecki S, Jaber S. Ventilator-induced diaphragmatic dysfunction: development and perspectives of the first mouse model. Am J Respir Crit Care Med 2011;183: A4245.

27. Picard M, Liang F, Hussain SN, Goldberg AL, Danialou G, Chaturvedi R, Matecki S, Jaber S, Des Rosiers C, Karpati G, et al. Mitochondrial 
dysfunction and lipid accumulation in the human diaphragm during mechanical ventilation. Am J Respir Crit Care Med 2011;183:A4257.

28. Jung B, Azuelos I, Li T, Liang F, Okazaki T, Picard M, Pauly M, Jaber S, Petrof BJ. Overexpression of peroxiredoxin-3, prevents ventilatorinduced diaphragmatic dysfunction in mice. Preliminary results. $\mathrm{Am}$ J Respir Crit Care Med 2012;185:A2705.

29. Matsushima S, Ide T, Yamato M, Matsusaka H, Hattori F, Ikeuchi M, Kubota T, Sunagawa K, Hasegawa Y, Kurihara T, et al. Overexpression of mitochondrial peroxiredoxin-3 prevents left ventricular remodeling and failure after myocardial infarction in mice. Circulation 2006;113:1779-1786.

30. Divangahi M, Balghi H, Danialou G, Comtois AS, Demoule A, Ernest S, Haston C, Robert R, Hanrahan JW, Radzioch D, et al. Lack of CFTR in skeletal muscle predisposes to muscle wasting and diaphragm muscle pump failure in cystic fibrosis mice. PLoS Genet 2009;5:e1000586.

31. Johnston TP. The p-407-induced murine model of dose-controlled hyperlipidemia and atherosclerosis: a review of findings to date. J Cardiovasc Pharmacol 2004;43:595-606.

32. Taivassalo T, Gardner JL, Taylor RW, Schaefer AM, Newman J, Barron MJ, Haller RG, Turnbull DM. Endurance training and detraining in mitochondrial myopathies due to single large-scale mtDNA deletions. Brain 2006;129:3391-3401.

33. Taivassalo T, Jensen TD, Kennaway N, DiMauro S, Vissing J, Haller RG. The spectrum of exercise tolerance in mitochondrial myopathies: a study of 40 patients. Brain 2003;126:413-423.

34. Yakes FM, Van Houten B. Mitochondrial DNA damage is more extensive and persists longer than nuclear DNA damage in human cells following oxidative stress. Proc Natl Acad Sci USA 1997;94:514-519.

35. Taylor RW, Turnbull DM. Mitochondrial DNA mutations in human disease. Nat Rev Genet 2005;6:389-402.

36. Murphy JL, Blakely EL, Schaefer AM, He L, Wyrick P, Haller RG, Taylor RW, Turnbull DM, Taivassalo T. Resistance training in patients with single, large-scale deletions of mitochondrial DNA. Brain 2008;131:2832-2840.

37. Taylor RW, Schaefer AM, Barron MJ, McFarland R, Turnbull DM. The diagnosis of mitochondrial muscle disease. Neuromuscul Disord 2004; 14:237-245.

38. Muller-Hocker J. Cytochrome-c oxidase deficient fibres in the limb muscle and diaphragm of man without muscular disease: an agerelated alteration. J Neurol Sci 1990;100:14-21.

39. Krishnan KJ, Reeve AK, Samuels DC, Chinnery PF, Blackwood JK, Taylor RW, Wanrooij S, Spelbrink JN, Lightowlers RN, Turnbull DM. What causes mitochondrial DNA deletions in human cells? Nat Genet 2008;40:275-279.

40. Chinnery PF, Howel D, Turnbull DM, Johnson MA. Clinical progression of mitochondrial myopathy is associated with the random accumulation of cytochrome- $c$ oxidase negative skeletal muscle fibres. J Neurol Sci 2003;211:63-66.

41. Bender A, Krishnan KJ, Morris CM, Taylor GA, Reeve AK, Perry RH, Jaros E, Hersheson JS, Betts J, Klopstock T, et al. High levels of mitochondrial DNA deletions in substantia nigra neurons in aging and Parkinson disease. Nat Genet 2006;38:515-517.

42. Kavazis AN, Talbert EE, Smuder AJ, Hudson MB, Nelson WB, Powers SK. Mechanical ventilation induces diaphragmatic mitochondrial dysfunction and increased oxidant production. Free Radic Biol Med 2009;46:842-850.

43. Whidden MA, Smuder AJ, Wu M, Hudson MB, Nelson WB, Powers SK Oxidative stress is required for mechanical ventilation-induced protease activation in the diaphragm. J Appl Physiol 2010;108:1376-1382.

44. Indo HP, Davidson M, Yen HC, Suenaga S, Tomita K, Nishii T, Higuchi M, Koga Y, Ozawa T, Majima HJ. Evidence of ROS generation by mitochondria in cells with impaired electron transport chain and mitochondrial DNA damage. Mitochondrion 2007;7:106-118.

45. St-Pierre J, Drori S, Uldry M, Silvaggi JM, Rhee J, Jager S, Handschin C, Zheng K, Lin J, Yang W, et al. Suppression of reactive oxygen species and neurodegeneration by the PGC-1 transcriptional coactivators. Cell 2006;127:397-408

46. Lee HY, Choi CS, Birkenfeld AL, Alves TC, Jornayvaz FR, Jurczak MJ Zhang D, Woo DK, Shadel GS, Ladiges W, et al. Targeted expression of catalase to mitochondria prevents age-associated reductions in mitochondrial function and insulin resistance. Cell Metab 2010;12: 668-674.

47. Schrauwen P, Schrauwen-Hinderling V, Hoeks J, Hesselink MK. Mitochondrial dysfunction and lipotoxicity. Biochim Biophys Acta 2010; 1801:266-271.

48. Bugger H, Abel ED. Molecular mechanisms for myocardial mitochondrial dysfunction in the metabolic syndrome. Clin Sci (Lond) 2008; 114:195-210

49. Canto C, Gerhart-Hines Z, Feige JN, Lagouge M, Noriega L, Milne JC, Elliott PJ, Puigserver P, Auwerx J. AMPK regulates energy expenditure by modulating NAD + metabolism and Sirt1 activity. Nature 2009;458:1056-1060.

50. Handschin C, Spiegelman BM. The role of exercise and PGC1alpha in inflammation and chronic disease. Nature 2008;454:463-469.

51. Canto C, Auwerx J. PGC-1alpha, Sirt1 and AMPK, an energy sensing network that controls energy expenditure. Curr Opin Lipidol 2009;20: 98-105.

52. Lin SJ, Ford E, Haigis M, Liszt G, Guarente L. Calorie restriction extends yeast life span by lowering the level of NADH. Genes Dev 2004;18:12-16

53. Canto C, Jiang LQ, Deshmukh AS, Mataki C, Coste A, Lagouge M, Zierath JR, Auwerx J. Interdependence of AMPK and Sirt1 for metabolic adaptation to fasting and exercise in skeletal muscle. Cell Metab 2010;11:213-219.

54. Zaloga GP, Willey S, Tomasic P, Chernow B. Free fatty acids alter calcium binding: a cause for misinterpretation of serum calcium values and hypocalcemia in critical illness. J Clin Endocrinol Metab 1987; 64:1010-1014.

55. Casaer MP, Mesotten D, Hermans G, Wouters PJ, Schetz M, Meyfroidt G, Van Cromphaut S, Ingels C, Meersseman P, Muller J, et al. Early versus late parenteral nutrition in critically ill adults. $N$ Engl $\mathrm{J}$ Med 2011;365:506-517.

56. Hermans G, Wilmer A, Meersseman W, Milants I, Wouters PJ, Bobbaers H, Bruyninckx F, Van den Berghe G. Impact of intensive insulin therapy on neuromuscular complications and ventilator dependency in the medical intensive care unit. Am J Respir Crit Care Med 2007;175:480-489.

57. Kukidome D, Nishikawa T, Sonoda K, Imoto K, Fujisawa K, Yano M, Motoshima H, Taguchi T, Matsumura T, Araki E. Activation of AMP-activated protein kinase reduces hyperglycemia-induced mitochondrial reactive oxygen species production and promotes mitochondrial biogenesis in human umbilical vein endothelial cells. Diabetes 2006;55:120-127.

58. Viscomi C, Bottani E, Civiletto G, Cerutti R, Moggio M, Fagiolari G, Schon EA, Lamperti C, Zeviani M. In vivo correction of Cox deficiency by activation of the AMPK/PGC-1alpha axis. Cell Metab 2011; 14:80-90.

59. Kane DA, Anderson EJ, Price JW III, Woodlief TL, Lin CT, Bikman BT, Cortright RN, Neufer PD. Metformin selectively attenuates mitochondrial $\mathrm{H}_{2} \mathrm{O}_{2}$ emission without affecting respiratory capacity in skeletal muscle of obese rats. Free Radic Biol Med 2010;49:1082-1087.

60. Timmers S, Konings E, Bilet L, Houtkooper RH, van de Weijer T, Goossens GH, Hoeks J, van der Krieken S, Ryu D, Kersten S, et al. Calorie restriction-like effects of 30 days of resveratrol supplementation on energy metabolism and metabolic profile in obese humans. Cell Metab 2011;14:612-622.

61. Camara AK, Lesnefsky EJ, Stowe DF. Potential therapeutic benefits of strategies directed to mitochondria. Antioxid Redox Signal 2010;13: 279-347. 